\title{
Barefoot Plantar Pressure Measurement in Chronic Exertional Compartment Syndrome.
}

Roscoe $D^{1,2}$, Roberts $A J^{1,4}$, Hulse $D^{1}$, Shaheen $A^{2}$, Hughes $M^{2}$, Bennett $A^{1,5}$

${ }^{1}$ Academic Department of Military Rehabilitation, Defence Medical Rehabilitation Centre, Headley Court, Epsom, Surrey, KT18 6JW, United Kingdom.

${ }^{2}$ Department of Biomedical Engineering, University of Surrey Postgraduate Medical School, Duke of Kent Building, University of Surrey, Guildford, Surrey, GU2 7TE.

${ }^{4}$ Department of Sport and Health Sciences, University of Exeter, College of Life and Environmental Sciences, St. Luke's Campus, Exeter, EX1 2LU.

${ }^{5}$ Leeds Institute of Molecular Medicine, University of Leeds, St James's University Hospital, Leeds, LS9 7TF.

Corresponding Author: Dr David Roscoe MRCGP, MFSEM, PhD, MPA Academic Department of Military Rehabilitation, Defence Medical Rehabilitation Centre, Headley Court, Epsom, Surrey, KT18 6JW, United Kingdom

e-mail: dave.roscoe314@mod.uk 


\section{ABSTRACT}

\section{Background}

Patients with Chronic Exertional Compartment Syndrome (CECS) have exercise limiting pain that subsides at rest. Diagnosis is confirmed by intramuscular compartment pressure (IMCP) measurement. Accompanying CECS, subjective changes to gait (foot slap) are frequently reported by patients. This has not previously been investigated. The aim of this study was to investigate differences in barefoot plantar pressure (BFPP) between CECS cases and asymptomatic controls prior to the onset of painful symptoms.

\section{Methods}

40 male military volunteers, 20 with symptoms of CECS and 20 asymptomatic controls were studied. Alternative diagnoses were excluded with rigorous inclusion criteria, magnetic resonance imaging and dynamic IMCP measurement. BFPP was measured during walking and marching. Data were analysed for: Stance Time (ST); foot progression angle (FPA); centre of force; plantarflexion rate after heel strike (IFFC-time); the distribution of pressure under the heel; and, the ratio between inner and outer metatarsal loading. Correlation coefficients of each variable with speed and leg length were calculated followed by ANCOVA or t-test. Receiver operating characteristic (ROC) curves were constructed for IFFC-time.

\section{Results}

Cases had shorter ST and IFFC-times than controls. FPA was inversely related to walking speed (WS) in controls only. The area under the ROC curve for IFFC-time ranged from $0.746(95 \% \mathrm{Cl}: 0.636-0.87)$ to $0.773(95 \% \mathrm{Cl}: 0.671-0.875)$ representing 'fair predictive validity'. 


\section{Conclusion}

Patients with CECS have an increased speed of ankle plantarflexion after heel strike that precedes the onset of painful symptoms likely resulting from a mechanical disadvantage of Tibialis Anterior. These findings provide further insight into the pathophysiology of CECS and support further investigation of this non-invasive diagnostic. The predictive value of IFFC-time in the diagnosis of CECS is comparable to post-exercise IMCP but falls short of dynamic IMCP measured during painful symptoms. 


\section{BACKGROUND}

The patient with anterior compartment CECS usually complains of exercise-limiting pain localised over the anterior compartment, which is relieved by rest. It is common for patients to report a description of fullness, tightness, or increased girth over the antero-lateral aspect of the leg ${ }^{18,19,23}$. The pain and associated symptoms of CECS commonly subside over a period of minutes following cessation of activity $46,49,61$ such that Exercise Induced Leg Pain (EILP) typically presents a diagnostic challenge to the practitioner as subsequent examination of the patient is typically normal ${ }^{10,22,42}$.

CECS, which is commonly bilateral $4,49,58$, has been defined as a painful condition in which exercise induces high pressure within a closed myofascial space, resulting in a decrease in tissue perfusion and ischaemia ${ }^{38,48}$ although the underlying pathophysiology has not been confirmed ${ }^{5,39}$. Recent evidence, from this same study group, has shown that in CECS, Intramuscular Compartment Pressure (IMCP) is elevated above that of controls immediately on standing at rest ${ }^{52}$. This divergence was amplified during a symptom-provoking exercise challenge suggesting that a structural component results in reduced compartment compliance ${ }^{52}$, presumed to be a result of an increase in fascial stiffness.

Subjective neurological and gait impairments often accompanying the pain in CECS include: first web-space paraesthesia and numbness and, if exercise persists beyond the onset of pain, a change to the gait pattern is frequently reported ${ }^{13}$. This typically manifests as foot-drop1 due to a loss of control of the foot at heel strike (Initial Foot Contact, IFC) $)^{3,60}$. This is often described as 'foot-slapping ${ }^{24}$ ' resulting from loss of function of, primarily, the Tibialis Anterior, Extensor Hallucis Longus and Deep Peroneal Nerve as it passes through the anterior compartment ${ }^{13}$.

Gait disturbance in CECS is infrequently reported in the literature ${ }^{17,53}$ but is commonly observed in military patients and those undergoing dynamic IMCP testing on a treadmill in our clinic. In extreme cases, patients report having tripped and fallen because of this loss of control of ankle dorsiflexion. This can be a dangerous occurrence in a military context and has occasionally been the trigger for patients to seek intervention.

The nature of military training, demanding intense determination and a willtosucceed, associated with perceived negative career implications of failure ${ }^{6}$, often results in EILP patients continuing well beyond the onset of painful symptoms. Results of an exercise protocol with dynamic IMCP measurement, designed to mimic this real-world situation where subjects continue exercising to the point of maximal pain rather than ceasing at the onset, were recently reported in this same study group ${ }^{52}$. It was demonstrated that the greatest diagnostic discrimination, in IMCP terms, corresponds to the period of maximal symptom provocation ${ }^{52}$. Patients often developed foot-slap well before the voluntary cessation of exercise or completion of the test protocol. There is no evidence in the literature of this phenomenon being investigated.

Little objective data is currently available regarding any biomechanical differences that might exist between patients with CECS and healthy controls. Treatment is 
usually surgical although conservative treatment options involving gait modification have been proposed with some reported success ${ }^{14,15,24}$. These are based on a theoretical 'off-loading' of the anterior compartment musculature through encouraging a transition from rear-foot to forefoot strike running.

Prospective studies assessing barefoot plantar pressure (BFPP) recordings in patients with overuse lower limb injuries have highlighted differences in loading characteristics associated with injury ${ }^{64,65}$. Within the military, plantar pressure during walking has been reported to be predictive of injury in a single small study ${ }^{20}$. BFPP variables related specifically to CECS however have not yet been identified. Where plantar pressure has been measured with the shod condition, this has been reported to be less sensitive in identifying risk factors for injury than when barefoot ${ }^{65}$.

We hypothesised that there is a difference in rates of plantarflexion and foot loading between CECS cases and asymptomatic controls. Accordingly, the aim of this study was to investigate differences in BFPP characteristics between IMCP-proven CECS cases and asymptomatic controls prior to the onset of painful symptoms. The variables chosen relate to the measurement of 'foot slap' as well as biomechanical and anthropometric parameters commonly assessed in clinical settings.

\section{METHODS}

\section{Participants}

20 consecutive male cases with symptoms consistent with CECS of the anterior compartment of the leg and 20 asymptomatic controls were recruited. This number was used as little evidence was available to support sample size calculation and this same study group was used in the previously reported IMCP study demonstrating statistical significance ${ }^{52}$. Cases were recruited from the Lower Limb Pain clinic at the

Defence Medical Rehabilitation Centre, Headley Court (Surrey, UK). Controls were recruited from the UK Armed Forces. The diagnosis of CECS was established from typical symptoms, with clinical examination and MRI excluding other pathologies before IMCP was performed. Cases had higher IMCP than controls $(114 \pm 32 \mathrm{mmHg}$ vs $68.7 \pm 22 \mathrm{mmHg}$ ) and reported pain in the anterior compartment within 10 minutes of loaded marching as previously reported ${ }^{52}$. The Ministry of Defence Research Ethics Committee granted ethical approval.

\section{Inclusion Criteria}

The inclusion criteria were: Male; Aged 18-40 (representing the typical age-range of UK military service personnel); $\mathrm{BMl}<35$; and, no lower limb length discrepancy $>2 \mathrm{~cm}$. Subjects required the following: symptoms of EILP consistent with a diagnosis of CECS, by definition affecting their ability to complete full duties; a negative MRI of the affected limb(s) and lumbar spine; no diagnosis other than CECS more likely; absence of multiple lower limb pathologies; and, no previous lower limb surgery. Healthy controls were included when they had: no lower limb 
pain in previous 12 months; no current pain at any site, including during exercise activities; no reliance on orthotics; and, could run pain-free for up to 20 minutes.

\section{Equipment}

BFPP was assessed using a $2 \mathrm{~m}$ pressure-plate (RSScan International, Belgium, $2 \mathrm{~m}$ $\times 0.4 \mathrm{~m} \times 0.02 \mathrm{~m}, 256$ lines at $120 \mathrm{~Hz}$ and 3 sensors per $\mathrm{cm} 2,16384$ sensors) permanently fitted flush to the floor of the laboratory. Data were extracted using Footscan® software (RSScan International, Version 7.97).

\section{Assessment Protocol (Data Collection)}

Measurements of height, leg length (LL), UK shoe size and body mass were performed using a stadiometer (SECA, UK), tape measure and medical grade scales (SECA, UK) respectively. Anthropometrics were collected to allow analysis of data in line with the recommendations of made by Hof that all gait data should be scaled to body size ${ }^{28}$.

Participants completed a barefoot dynamic calibration and four familiarisation traverses of the laboratory (approximately $18 \mathrm{~m}$ ) over the BFPP walkway.

Participants were then asked to walk at their natural pace and march 'as if they were doing their military fitness test'. Foot placement order was self-selected. Ten successful trials were obtained per participant. A trial was considered successful if it was completed without visible adjustment in approaching or traversing of the pressure plate and foot strikes occurred within the required area. Speed was assessed post-hoc using analysis of video camera data.

The statistical relationship of speed with each variable was assessed to determine the requirement to include speed as a covariate in the analysis. This is in line with studies of conditions, unlike CECS, in which gait speed is considered a fundamental component of the pathology and with the recommendation of Rodgers 50 that the effect of speed should be considered in all biomechanical data.

\section{Barefoot Plantar Pressure Measurements}

Footscan $\AA$ software defined ten anatomical zones (Figure 1).

The calculated variables were defined as follows:

1. Stance time (ST, ms)

2. FPA: Foot Progression Angle; the angle made between the line of walking progression and the long axis of the foot defined by a line drawn between the boundary of $\mathrm{HM}-\mathrm{HL}$ and $\mathrm{M} 2-3^{8}$.

3. COFx: The mean of the medial-lateral displacement of centre of force (COF) curves. The axis is perpendicular to the longitudinal axis of the foot with a higher value indicating more medial displacement.

4. IFFC-time (plantarflexion rate): Time(ms) from IFC to initial full forefoot contact when all metatarsal heads, M1-5 (IFFC), are in contact with the ground. 
5. $\mathrm{HM} / \mathrm{HL}$ : The medial-lateral distribution of pressure under the heel was measured as $\mathrm{HM} /[\mathrm{HM}+\mathrm{HL}]$ at IFC, $5 \%$ of ST and at IFFC. Higher measures indicate medial distribution of the total pressure under the heel which has been suggested to be a marker of pronation56 but no literature is available showing an association with movement.

6. FORE: The ratio, between inner and outer metatarsal loading: 100((M1-M5)/Zone average). As previous, higher measures indicate a more medial distribution of PP however this has not previously been shown to be associated with a specific movement.

For each variable the mean of all successful foot strikes at each speed was calculated and used in subsequent analysis. Scilab v5.3.2 (INRIA, France) was used to process data export from Footscan®.

IMCP results for this study group have already been described and a detailed analysis published previously ${ }^{52}$.

\section{Statistical Analysis}

SPSS (Version 20, SPSS Inc., Chicago, IL, USA) with a significance level of 0.05 was used for all analyses. Homogeneity of variance was assessed using Levene's test ${ }^{25,68}$. The relationship of each BFPP variable with LL and walking speed (WS) was checked using Pearson's correlation coefficient in accordance with

recommendations ${ }^{28,44,50}$. Variables that were correlated with either LL or WS were analysed using ANCOVA ${ }^{29,62,66}$ as reported in similar studies ${ }^{2,41}$. In other cases, independent samples t-tests were used.

BFPP variables for the right and left leg were analysed separately. Where no differences were seen in the results of the tests for either leg, values for the left leg were chosen as representative ${ }^{41}$. Similarly, where the results of the tests were not dependent on the speed tested, values for WS were chosen as representative.

Receiver operating characteristic (ROC) curves were constructed for IFFC-time to determine specificity and sensitivity (left and right combined). Curves were generated for walking and marching to compare diagnostic ability. The area under the curve was calculated as an indicator of overall diagnostic ability59. Cut-offs were generated to maximise the sum of sensitivity and specificity with a minimum of $60 \%$ set for each measure.

\section{RESULTS}

Cases were aged between 21-40 (mean=27.5, $\mathrm{sd}=4.9)$; controls between 19-40 (mean=28.3, $s d=7.4)$. Controls $(1.81 \mathrm{~m} \square 0.06)$ were significantly taller $(\mathrm{p}=0.002)$ than cases (1.71m $\square 0.13$ ); although there were no differences in weight or heightto-leg length ratio. One control subject's data could not be processed correctly by the RSScan software due to large feet (UK size 13) and was excluded from analysis. 
LL was not significantly correlated with any BFPP variables (Table 1). WS correlated with FPA and ST for all four conditions; ANCOVA was carried out on these variables with speed as the covariate. IFFC-time was not correlated with WS. HMHL variables showed varying degrees and directions of association with WS; in each case only one side at one speed was significant. HMHL variables were therefore tested using the t-test.

The ANCOVA assumption of the homogeneity of regression slopes was not met by the FPA (all conditions) and the ST variable in the marching condition (Figure 2) however when the difference is small and group sizes are equal, this type of heterogeneity was shown early on in the literature to be an insignificant problem ${ }^{32}$ with the ANCOVA remaining robust and valid11. ANCOVA results agree with t-tests using the same variables.

Cases had significantly shorter ST and IFFC-times than controls (Table 2) however there were no differences in stride-length when normalised to leg length, as per the recommendations of $\mathrm{Hof}^{28}$, for this study group. The differences in ST and IFFC-time were consistent between left and right feet and at both speeds. While there were some significant differences present in the other variables, these were not consistent between walking and marching.

The area under the ROC curve ranged from $0.746(95 \% \mathrm{Cl}: 0.636-0.87)$ to 0.773 (95\% Cl: 0.671-0.875) representing 'fair predictive validity' for IFFC-time. Optimal cutoff values and indices of diagnostic accuracy for each condition are described in Table 3.

\section{DISCUSSION}

These results suggest differences exist between CECS cases and controls FPA adaptation to increasing WS (Figure 2). Previous studies suggested that, in the normal state, FPA reduces as WS increases ${ }^{7,26,57,63}$. Shanthikumar et al. reported a mean FPA of $13.3^{\circ}$ with a WS of $1.33 \mathrm{~m} / \mathrm{s} 56$. This is consistent with the reduced FPA reported in Table 2 as the overall mean WS in this study was $1.7 \mathrm{~m} / \mathrm{s}$. Controls reduced FPA with WS but cases demonstrated minimal adaptation. It is not clear what is responsible for this effect although abnormal TA activity has previously been implicated in FPA30. This idea fits with the infero-medial oblique orientation of the TA across the axis of the shank as well as the postulated role of TA in the walk-run transition $36,54,55$. If TA is operating at a mechanical disadvantage in CECS, as suggested by the increased rate of plantarflexion reported here, this might account for this reduced ability to adapt to increasing WS. Alternatively, this could be the result of kinematic differences, further up the kinetic chain, which cannot be identified with BFPP alone. Despite the differences observed in the regression slopes for FPA the results did not reach significance using either t-tests or ANCOVA however the relationship remains interesting warranting further kinematic study to better define the nature of the motion taking place. The effect of fatigue and pain should also be further investigated as CECS is usually only discussed in the presence of pain. 
In this context both conditions might be expected to amplify the effect sizes on BFPP seen in this study.

HMHL results suggest that CECS patients have more medial pressure distribution under the heel at both IFC and $5 \%$ of the gait cycle after IFC although this only reached significance on the right side. This was not shown during walking (Table 2). Shanthikumar et al. demonstrated that HM force was greater than HL force, during the initial foot contact phase, indicating calcaneal pronation56 although this has not been proven to be associated with rearfoot movement. This is also what is seen throughout the data reported here. This current study shows that the distribution of pressure became more medially located in all cases from HMHL-IFC to HMHL-5\%. The differences between CECS cases and controls were only significant during marching suggesting this activity is an ingrained adaption differing from the subjects' normal gait pattern; further kinematic studies are warranted to investigate this.

The temporal data reported in Table 1 confirm that in both groups ST is inversely proportional to WS in this study $(r=-0.86$ to $-0.89, p<0.001)$. The shorter IFFC observed in CECS patients in this study accounted for between $32-36 \%$ of the shorter stance time observed; yet IFFC accounts for only $13-16 \%$ of stance time. The mechanism for the remaining unexplained variance is unclear.

This study is the first to report that, despite the absence of painful symptoms at the time of testing, patients with CECS demonstrate a significantly increased rate of plantarflexion after IFC (Table 1). This suggests a diminished ability of the anterior compartment musculature to control the lowering of the foot during plantarflexion in CECS. Data was collected in a rested state using a non-fatiguing or symptom provoking protocol and differences occurred from the start of data collection confirming fatigue of TA at the time of testing is not the explanation.

The diagnostic cut-off values for IFFC for anterolateral CECS are not dissimilar in their diagnostic potential to those recently reported for the widely adopted Pedowitz criteria for invasive IMCP measurement ${ }^{43,52}$. Whilst the likelihood ratios fall well short of the utility of the IMCP results reported using continuous dynamic IMCP measurement in this same study group52, it is worthy of note that the IFFC values were collected in an asymptomatic setting. In comparison, both the Pedowitz criteria and dynamic IMCP were collected during or after provocation of painful symptoms ${ }^{52}$. Unlike IMCP, BFPP represents a non-invasive investigation therefore deserving further evaluation including in the presence of painful symptoms.

New insights into the mechanism resulting in movement of the ankle joint after IFC have recently been reported. Chleboun et al. concluded that there is essentially no eccentric lengthening of the TA muscle after IFC such that lowering of the foot occurs through tendon stretch whilst the muscle contracts isometrically9.This suggests that the stiffness of the TA tendon ${ }^{12,35}$ is a vital element in the effective functioning of the anterior compartment. Therefore, if IFFC is reduced in CECS cases it is plausible that this is due to stretching of TA tendon although inherent weakness in the muscle cannot be excluded based on these studies alone. 
Maganaris et al. showed that some of this tendon lengthening can be accommodated by flex in the anterior retinaculum of the ankle under which the TA tendon runs like a pulley. The effective moment arm of TA shortens from rest to maximal isometric contraction by anterior displacement of the tendon action line by $0.8-1.2 \mathrm{~cm}$ as a result of this stretching of the retinaculum ${ }^{33,34}$. Footwear constricting this displacement might therefore effectively increase the distance that the TA tendon has to travel in order to slow plantarflexion at IFC. Future studies, including plantar pressure and kinematics, should therefore consider the role of (military) footwear in the possible compression of the extensor retinaculum of the ankle and stretch of TA.

\section{Limitations}

This data cannot attribute the reduced control of plantarflexion to a relative weakness of the TA versus an effective lengthening or change in the elastic composition of the TA tendon preventing the transmission of the effect of TA contraction to the foot. This study also cannot confirm if this increased rate of plantarflexion is causal or resultant from CECS; further prospective studies are required to investigate this. It has been shown that the elastic properties of tendons can be modified over time through training practices ${ }^{45,67}$ and this is appealing in the context of CECS being an acquired rather that inherent condition.

The correlation results in Table 1 demonstrate that the only BFPP measurement significantly correlated with WS was FPA ( $r=0.01$ to $0.21, P=0.01$ to 0.21$)$. This is consistent with previous studies $26,50,51,56$ where FPA was shown to reduce with increasing WS and is reassuring in this context.

This is the first study to investigate the relationship of IFFC with walking speed. These results indicate that IFFC is not significantly correlated to walking speed, however IFFC is a component of stance time which has previously been shown to be inversely proportional to walking speed ${ }^{40}$. This suggests that IFFC is independent of stance time. IFFC results were crosschecked using ANCOVA with speed as the covariate. The results are reassuringly in agreement and do not improve on the level of significance suggesting that, under similar experimental conditions, either method is suitable should accurate control of speed not be possible in the initial study design.

\section{CONCLUSIONS}

Patients with symptoms of anterolateral CECS of the leg have an increased rate of plantarflexion after IFC preceding the onset of pain. This is proposed to be as a result of a mechanical disadvantage of TA either through muscle weakness or elongation of the tendon. Further studies using EMG and kinematics as well as in the presence of painful symptoms are now recommended to address these questions and confirm the diagnostic utility of PP measurement in CECS. 


\section{REFERENCES}

[1] Baker JF, Lui DF, Kiely PD, Synnott KA. Foot drop--an unusual presentation of exertional compartment syndrome. Clin J Sport Med. 2009;19(3):236-237. doi:10.1097/JSM.0b013e3181a39b04.

[2] Becker J, Howey RJ, Osternig LR, James S. Plantar pressure differences between rearfoot and midfoot striking runners during shod running. The 2012 ASB Annual Meeting, Gainesville, FL. 2012.

[3] Birtles D, Rayson M, Jones D, Padhiar N, Casey A, Newham D. Effect of eccentric exercise on patients with chronic exertional compartment syndrome. Eur J Appl Physiol. 2003;88(6):565-571. doi:10.1007/s00421002-0740-z.

[4] Blackman PA. Review of chronic exertional compartment syndrome in the lower leg. Med Sci Sports Exerc. 2000;32(Suppl 3):S4-S10.

[5] Bong MR, Polatsch DB, Jazrawi LM. Chronic exertional compartment syndrome: diagnosis and management. Bulletin of the NYU Hospital for Joint Diseases. 2004.

[6] Braithwaite, M., Nicholson, G., Thornton, R., Jones, D., Simpson, R., McLoughin, D. Jenkins, D. 2009. Armed Forces occupational health--a review. Occup Med (Lond). Dec;59(8):528-38.

[7] Caravaggi P, Leardini A, Crompton R. Journal of Biomechanics. Journal of Biomechanics. 2010;43(12):2425-2433. doi:10.1016/j.jbiomech.2010.04.015.

[8] Cavanagh PR, Rodgers MM. The arch index: a useful measure from footprints. Journal of Biomechanics. 1987.

[9] Chleboun GS, Busic AB, Graham KK, Stuckey HA. Fascicle Length Change of the Human Tibialis Anterior and Vastus Lateralis During Walking. J Orthop Sports Phys Ther. 2007;37(7):372-379. doi:10.2519/jospt.2007.2440.

[10] Clanton, T., Solcher. B. W., 1994. Chronic leg pain in the athlete. Clinical Journal of Sport Medicine, 13, pp.743-759.

[11] D'Alonzo KT. The Johnson-Neyman Procedure as an Alternative to ANCOVA. Western Journal of Nursing Research. 2004;26(7):804-812. doi:10.1177/0193945904266733.

[12] De Zee M, Voigt M. Assessment of functional series elastic stiffness of human dorsiflexors with fast controlled releases. J Appl Physiol. 2002;93(1):324-329. doi:10.1152/japplphysiol.00696.2001.

[13] Dharm-Datta S, Minden DF, Rosell PA, Hill PF, Mistlin A, Etherington J. Dynamic pressure testing for chronic exertional compartment syndrome in the UK military population. J R Army Med Corps. 2013;159(2):114-118. doi:10.1136/jramc2013-000033. 
[14] Diebal AR, Gregory R, Alitz C, Gerber JP. Effects of forefoot running on chronic exertional compartment syndrome: a case series. Int J Sports Phys Ther.

$2011 ; 6(4): 312-321$.

[15] Diebal AR, Gregory R, Alitz C, Gerber JP. Forefoot Running Improves Pain and Disability Associated With Chronic Exertional Compartment Syndrome. The American Journal of Sports Medicine. 2012;40(5):1060-1067. doi:10.1177/0363546512439182.

[16] Edmundsson D, Toolanen G, Sojka P. Chronic compartment syndrome also affects nonathletic subjects: a prospective study of 63 cases with exercise-induced lower leg pain. Acta Orthop. 2007;78(1):136-142. doi:10.1080/17453670610013547.

[17] Edwards P. Exertional compartment syndrome of the leg: steps for expedient return to activity. Phys Sports Med. 1996:371-373.

[18] Edwards PH, Wright ML, Hartman JF. A Practical Approach for the differential Diagnosis of Chronic Leg Pain in the Athlete. American Journal of Sports Medicine. 2005;33:1241-1249. doi:10.1177/0363546505278305.

[19] Fraipont MJ, Adamson GJ. Chronic Exertional Compartment Syndrome. Journal of the American Academy of Orthopaedic Surgeons. 2003;11(4):268-276.

[20] Franklyn-Miller A, Bilzon J, Wilson C, McCrory P. Can RSScan footscan® D3D ${ }^{\mathrm{TM}}$ software predict injury in a military population following plantar pressure assessment? A prospective cohort study. The Foot. 2014;24(1):610. doi:10.1016/j.foot.2013.11.002.

[21] Franklyn-Miller A, Roberts A, Hulse D, Foster J. Biomechanical overload syndrome: defining a new diagnosis. British Journal of Sports Medicine. 2012;0(2012):201209124. doi:10.1136/bjsports-2012-091241.

[22] French E, Price W. Anterior Tibial Pain. British Medical Journal. 1962;17(2):1291-1296.

[23] Friedericson M, Wun CJ. Differential diagnosis of leg pain in the athlete. Journal of the American Academy of Orthopaedic Surgeons. 2003;93:321324.

[24] Gibson AR. Chronic Exertional Compartment Syndrome and Forefoot Striking: A Case Study. International journal of athletic therapy \& training. 2013;18(6):24-26.

[25] Glass GV. Testing Homogeneity of Variances. American Educational Research Journal. 1966;3(3):187. doi:10.2307/1161802.

[26] Hastings MK, Gelber JR, Isaac EJ, Bohnert KL, Strube MJ, Sinacore DR. Foot progression angle and medial loading in individuals with diabetes mellitus, peripheral neuropathy, and a foot ulcer. Gait \& Posture. 2010;32(2):237-241. doi:10.1016/j.gaitpost.2010.05.004.

[27] Hershman E, Touliopolis S. Lower Leg Pain: diagnosis and treatment of compartment syndromes and other pain syndromes of the leg. Sports Med. 1999;27:193-204. 
[28] Hof AL. Scaling gait data to body size. Gait \& Posture. April 1996:222-223.

[29] Huitema B. The Analysis of Covariance and Alternatives. John Wiley \& Sons; 2011.

[30] Karol LA, Concha MC, Johnston CE. Gait analysis and muscle strength in children with surgically treated clubfeet. J Pediatr Orthop. 1997;17(6):790795.

[31] Keppel G. Design and Analysis: a Researcher's Handbook (3rd Ed.). PrenticeHall, Inc; 1991.

[32] Levene H. Contributions to Probability and Statistics: Essays in Honour of Harold Hotlling. Stanford University Press 1960.

[33] Maganaris CN, Baltzopoulos V, Sargeant AJ. Changes in the tibialis anterior tendon moment arm from rest to maximum isometric dorsiflexion: in vivo observations in man. Clinical Biomechanics. 1999.

[34] Maganaris CN, Paul JP. In vivo human tendinous tissue stretch upon maximum muscle force generation. Journal of Biomechanics. 2000;33(11):1453-1459. doi:10.1016/S0021-9290(00)00099-3.

[35] Maganaris CN, Paul JP. In vivo human tendon mechanical properties. The Journal of Physiology. 1999;521 Pt 1:307-313.

[36] Malcolm P, Segers V, Van Caekenberghe I, De Clercq D. Experimental study of the influence of the $\mathrm{m}$. tibialis anterior on the walk-to-run transition by means of a powered ankle-foot exoskeleton. Gait \& Posture. 2009;29(1):6-10. doi:10.1016/j.gaitpost.2008.05.016.

[37] Mavor G. The Anterior Tibial Syndrome. British Journal of Bone and Joint Surgery. 1956;38:513-517.

[38] Mohler LR, Styf JR, Pedowitz RA, Hargens AR, Gershuni DH. Intramuscular Deoxygenation during Exercise in Patients Who Have Chronic Anterior Compartment Syndrome of the Leg. J Bone Joint Surg Am. 1997;79(6):844-849.

[39] Mubarak SJ, Pedowitz RA, Hargens AR. Compartment Syndromes. Current Orthopaedics. 1989;3:36-40.

[40] Murray MP, Kory RC, Clarkson BH. Walking Patterns in Healthy Old Men. Journal of Gerontology. 1969;24(2):169-178. doi:10.1093/geronj/24.2.169.

[41] Nieuwboer AA, Weerdt WD, Dom R. Plantar force distribution in Parkinsonian gait. A comparison oetween patients and age-matched control subjects.

Scandinavian journal of rehabilitation medicine 1999;31(3):185.

[42] Paik RS, Pepples D, Hutchinson MR. Chronic exertional compartment syndrome. BMJ. 2013;346(jan15_2):33. doi:10.1136/bmj.f33.

[43] Pedowitz RA., 1990. Modified criteria for the objective diagnosis of chronic compartment syndrome of the leg. Am J Sports Med, 18, pp.35-40. 
[44] Pierrynowski MR, Galea V. Enhancing the ability of gait analyses to differentiate between groups: scaling gait data to body size. January 2001:193-201.

[45] Pousson M, Pérot C, Goubel F. Stiffness changes and fibre type transitions in rat soleus muscle produced by jumping training. Pflugers Arch. 1991;419(2):127130.

[46] Pupka A, Bogdan J, Lepiesza A, Rojek A, Szyber PP. Sport Related Compression Syndromes - Review of the Literature. Medicina Sportiva. 2010;14(2):83-89. doi:10.2478/v10036-010-0016-3.

[47] Puranen OS. Athletes' Leg Pains. British Journal of Sports Medicine. 1979;13:92-97. doi:10.1136/bjsm.13.3.92.

[48] Qvarfordt PP, Christenson JTJ, Eklöf BB, Ohlin PP, Saltin BB. Intramuscular pressure, muscle blood flow, and skeletal muscle metabolism in chronic anterior tibial compartment syndrome. Clin Orthop Relat Res. 1983;(179):284-290.

[49] Richard F Pell IV, Khanuja HS, Cooley GR. Leg pain in the Running athlete. Journal of the American Academy of Orthopaedic surgery. 2004;12(6):396-404. http://www.jaaos.org/cgi/content/abstract/12/6/396.

[50] Rodgers MM. Dynamic biomechanics of the normal foot and ankle during walking and running. Phys Ther. 1988;68(12):1822-1830.

[51] Rodgers MM. Dynamic Foot Biomechanics. J Orthop Sports Phys Ther. 1995;21(6):306-316. doi:10.2519/jospt.1995.21.6.306.

[52] Roscoe D, Roberts AJ, Hulse D. Intramuscular Compartment Pressure Measurement in Chronic Exertional Compartment Syndrome: New and Improved Diagnostic Criteria. The American Journal of Sports Medicine. 2014;43(2):392-398. doi:10.1177/0363546514555970.

[53] Rowdon G, Richardson, J., Hoffman, P., Zaffer, M., Barill, E., 2001. Chronic Anterior Compmartment Syndrome and Deep Peroneal Nerve Function. Clinical Journal of Sport Medicine, 11, pp.229-233.

[54] Segers V, De Smet K, Van Caekenberghe I, Aerts P, De Clercq D. Biomechanics of spontaneous overground walk-to-run transition. J Exp Biol. 2013;216(Pt 16):3047-3054. doi:10.1242/jeb.087015.

[55] Segers V, Lenoir M, Aerts P, De Clercq D. Influence of M. tibialis anterior fatigue on the walk-to-run and run-to-walk transition in non-steady state locomotion. Gait \& Posture. 2007;25(4):639-647.

doi:10.1016/j.gaitpost.2006.07.008.

[56] Shanthikumar S, Low Z, Falvey E, McCrory P, Franklyn-Miller A. The effect of gait velocity on calcaneal balance at heel strike; Implications for orthotic prescription in injury prevention. Gait \& Posture. 2010;31(1):9-12.

doi:10.1016/j.gaitpost.2009.08.003. 
[57] Simic M, Wrigley TV, Hinman RS, Hunt MA, Bennell KL. Altering foot progression angle in people with medial knee osteoarthritis: the effects of varying toe-in and toe-out angles are mediated by pain and malalignment. Osteoarthr Cartil. 2013;21(9):1272-1280. doi:10.1016/j.joca.2013.06.001.

[58] Slimmon D, Bennell K, Brukner P, Crossley K, Bell SN. Long-Term Outcome of Fasciotomy with Partial Fasciectomy for Chronic Exertional Compartment Syndrome of the Lower Leg. The American Journal of Sports Medicine. 2002;30(4):581-588.

[59] Tape TG. Interpreting Diagnostic Tests. University of Nebraska Medical Center 2004: Http://Darwin.Unmc.Edu/Dxtests (Accessed November 2013).

[60] Tweed JL, Barnes MR. Is eccentric muscle contraction a significant factor in the development of chronic anterior compartment syndrome? A review of the literature. Foot (Edinb). 2008;18(3):165-170. doi:10.1016/j.foot.2008.06.005.

[61] Tzortziou V, Maffuli N, Padhiar N. Diagnosis and Management of Chronic Exertional Compartment Syndrome (CECS) in the United Kingdom. Clinical Journal of Sports Medicine. 2006;16:209-214.

[62] Vincent W, Weir J. Statistics in Kinesiology-4th Edition. Human Kinetics; 1994.

[63] Warren GL, Maher RM, Higbie EJ. Temporal patterns of plantar pressures and lower-leg muscle activity during walking: effect of speed. Gait \& Posture. 2004;19(1):91-100. doi:10.1016/S0966-6362(03)00031-6.

[64] Willems TM, De Clercq D, Delbaere K, Vanderstraeten G, De Cock A, Witvrouw E. A prospective study of gait related risk factors for exerciserelated lower leg pain. Gait \& Posture. 2006;23(1):91-98. doi:10.1016/j.gaitpost.2004.12.004.

[65] Willems TM, Witvrouw E, De Cock A. Gait-related risk factors for exerciserelated lower-leg pain during shod running. Medicine and Science in Sports and Exercise. 2007;39(2), 330.

[66] Wilson JLA. Clinical Biomechanics. Challenges in dealing with walking speed in knee osteoarthritis gait analyses. 2012;27(3):210-212.

doi:10.1016/j.clinbiomech.2011.09.009.

[67] Woo SL, Gomez MA, Amiel D, Ritter MA, Gelberman RH, Akeson WH. The effects of exercise on the biomechanical and biochemical properties of swine digital flexor tendons. J Biomech Eng. 1981;103(1):51-56. 
Table 1 - Pearson's correlation coefficient for variables of interest and walking speed and leg length with chosen analysis method for each variable. Ranges represent differences between walking speeds and side evaluated. *Single value was significant, t-test chosen as r-values cross zero. (FPA, foot progression angle; IFFC, initial forefoot contact; COFx, centre of force; FORE, ratio between inner and outer metatarsal loading; $\mathrm{HMHL}$, medial-lateral distribution of pressure under heel at heel strike, $5 \%$ of gait cycle and initial forefoot contact)

\begin{tabular}{|c|c|c|c|c|c|}
\hline Variable & $\begin{array}{c}\text { Speed } \\
\text { r-value } \\
\text { (range) }\end{array}$ & $\begin{array}{c}\text { Speed } \\
\text { p-value } \\
\text { (range) }\end{array}$ & $\begin{array}{c}\text { Leg Length } \\
\text { r-value } \\
\text { (range) }\end{array}$ & $\begin{array}{c}\text { Leg Length } \\
\text { p-value } \\
\text { (range) }\end{array}$ & $\begin{array}{c}\text { Analysis } \\
\text { method }\end{array}$ \\
\hline FPA & -0.21 to -0.40 & 0.01 to 0.21 & -0.14 to 004 & 0.41 to 0.89 & $\begin{array}{c}\text { ANCOVA - } \\
\text { speed }\end{array}$ \\
\hline IFFC-time & -0.12 to -0.19 & 0.20 to 0.46 & 0.02 to 0.13 & 0.42 to 0.90 & t-test \\
\hline Stance time & -0.46 to -0.73 & $<0.001$ to 0.003 & 0.18 to 0.28 & 0.09 to 0.27 & $\begin{array}{c}\text { ANCOVA - } \\
\text { speed }\end{array}$ \\
\hline COFx & 0.20 to -0.01 & 0.23 to 0.96 & -0.13 to 0.03 & 0.45 to 0.88 & t-test \\
\hline FORE & -0.05 to 0.16 & 0.34 to 0.82 & -0.21 to -0.12 & 0.19 to 0.45 & t-test \\
\hline HMHL-IFC & -0.46 to 0.41 & 0.01 to $0.78^{*}$ & -0.22 to -0.05 & 0.18 to 0.74 & t-test \\
\hline HMHL-5 & -0.22 to 0.37 & 0.018 to $0.36^{*}$ & -0.20 to -0.05 & 0.22 to 0.78 & t-test \\
\hline HMHL-IFFC & -0.012 to 0.29 & 0.08 to 0.94 & -0.09 to 0.02 & 0.59 to 0.88 & t-test \\
\hline
\end{tabular}


Table 2 - Comparison of differences between groups. AANCOVA F-Value reported for stance time and FPA data in brackets. BMean adjusted for effect of covariate (speed) for ANCOVA analysis. ADJAdjusted value used. (FPA, foot progression angle; IFFC, initial forefoot contact; COFx, centre of force; FORE, ratio between inner and outer metatarsal loading; HMHL, medial-lateral.

\begin{tabular}{|c|c|c|c|c|c|c|c|c|}
\hline Variable & Condition & t-value ${ }^{A}$ & p-value & $\begin{array}{c}\text { Mean } \\
\text { Controls }\end{array}$ & $\begin{array}{c}\text { SE } \\
\text { Controls }\end{array}$ & $\begin{array}{l}\text { Mean } \\
\text { Cases }\end{array}$ & $\begin{array}{c}\text { SE } \\
\text { Cases }\end{array}$ & Mean Diff \\
\hline \multirow{4}{*}{$\begin{array}{c}\mathrm{FPA}^{\mathrm{A}, \mathrm{B}} \\
\left(^{\circ}\right)\end{array}$} & L Walk & $\begin{array}{c}-1.88 \\
(1.35) \\
\end{array}$ & $\begin{array}{c}0.07 \\
(0.25) \\
\end{array}$ & $\begin{array}{c}11.2 \\
(10.6) \\
\end{array}$ & $\begin{array}{c}1.6 \\
(1.4) \\
\end{array}$ & $\begin{array}{c}7.6 \\
(8.2) \\
\end{array}$ & $\begin{array}{c}1.1 \\
(1.4)\end{array}$ & $\begin{array}{c}-3.6 \\
(-2.4)\end{array}$ \\
\hline & R Walk & $\begin{array}{l}-1.33 \\
(0.14) \\
\end{array}$ & $\begin{array}{c}0.19 \\
(0.71) \\
\end{array}$ & $\begin{array}{c}13.5 \\
(12.5)\end{array}$ & $\begin{array}{c}1.4 \\
(1.3)\end{array}$ & $\begin{array}{c}11.1 \\
(11.8)\end{array}$ & $\begin{array}{c}1.2 \\
(1.3)\end{array}$ & $\begin{array}{l}-2.4 \\
(-0.7)\end{array}$ \\
\hline & L March & $\begin{array}{l}-1.49 \\
(2.6)\end{array}$ & $\begin{array}{c}0.14 \\
(0.11)\end{array}$ & $\begin{array}{c}10.5 \\
(11.0)\end{array}$ & $\begin{array}{c}1.5 \\
(1.4)\end{array}$ & $\begin{array}{c}7.7 \\
(7.9)\end{array}$ & $\begin{array}{c}1.2 \\
(1.3)\end{array}$ & $\begin{array}{l}-2.9 \\
(-3.2)\end{array}$ \\
\hline & R March & $\begin{array}{c}-0.74 \\
(0.10)\end{array}$ & $\begin{array}{c}0.46 \\
(0.76) \\
\end{array}$ & $\begin{array}{c}12.8 \\
(12.4)\end{array}$ & $\begin{array}{c}1.2 \\
(1.2)\end{array}$ & $\begin{array}{c}11.6 \\
(11.9)\end{array}$ & $\begin{array}{c}1.1 \\
(1.1)\end{array}$ & $\begin{array}{c}-1.3 \\
(-0.53)\end{array}$ \\
\hline \multirow{4}{*}{$\begin{array}{c}\text { Stance } \\
\text { time } \\
\text { (ms) }\end{array}$} & L Walk & $\begin{array}{c}5.04 \\
(17.3) \\
\end{array}$ & $\begin{array}{c}<0.001 \\
(<0.001)\end{array}$ & $\begin{array}{c}602.4 \\
(590.0) \\
\end{array}$ & $\begin{array}{c}8.1 \\
(6.8) \\
\end{array}$ & $\begin{array}{c}540.7 \\
(550.0) \\
\end{array}$ & $\begin{array}{c}9.1 \\
(6.4) \\
\end{array}$ & $\begin{array}{c}61.7 \\
(40.0)\end{array}$ \\
\hline & R Walk & $\begin{array}{c}4.61 \\
(12.7)\end{array}$ & $\begin{array}{l}<0.001 \\
(0.001)\end{array}$ & $\begin{array}{c}600.4 \\
(587.2) \\
\end{array}$ & $\begin{array}{c}8.7 \\
(7.5)\end{array}$ & $\begin{array}{c}539.6 \\
(549.3)\end{array}$ & $\begin{array}{c}9.8 \\
(7.1)\end{array}$ & $\begin{array}{c}60.8 \\
(37.8)\end{array}$ \\
\hline & L March & $\begin{array}{c}3.31 \\
(10.1)\end{array}$ & $\begin{array}{c}0.002 \\
(0.003)\end{array}$ & $\begin{array}{c}539.6 \\
(531.5) \\
\end{array}$ & $\begin{array}{c}9.7 \\
(7.6) \\
\end{array}$ & $\begin{array}{c}493.6 \\
(498.1) \\
\end{array}$ & $\begin{array}{c}8.7 \\
(7.0)\end{array}$ & $\begin{array}{c}43.0 \\
(33.4)\end{array}$ \\
\hline & R March & $\begin{array}{l}2.92 \\
(6.0)\end{array}$ & $\begin{array}{c}0.006 \\
(0.019)\end{array}$ & $\begin{array}{c}537.3 \\
(531.3) \\
\end{array}$ & $\begin{array}{l}11.9 \\
(8.9) \\
\end{array}$ & $\begin{array}{c}497.1 \\
(501.3)\end{array}$ & $\begin{array}{c}9.2 \\
(8.2) \\
\end{array}$ & $\begin{array}{c}40.2 \\
(30.1)\end{array}$ \\
\hline \multirow{4}{*}{$\begin{array}{l}\text { COFx } \\
(\mathrm{mm})\end{array}$} & L Walk & 1.74 & 0.09 & -5.2 & 0.46 & -3.9 & 0.57 & 1.28 \\
\hline & R Walk & 0.23 & 0.82 & -3.6 & 0.60 & -3.4 & 0.57 & 0.19 \\
\hline & L March & 2.11 & 0.04 & 2.8 & 0.48 & 4.2 & 0.48 & 1.43 \\
\hline & R March & 0.21 & 0.83 & 4.3 & 0.46 & 4.4 & 0.55 & 0.15 \\
\hline \multirow{4}{*}{ FORE } & L Walk & 1.01 & 0.32 & 3.2 & 2.4 & 6.8 & 2.6 & 3.61 \\
\hline & R Walk & 0.55 & 0.59 & 7.0 & 2.9 & 9.0 & 2.4 & 2.93 \\
\hline & L March & 0.67 & 0.50 & 13.8 & 3.1 & 16.7 & 3.0 & 2.07 \\
\hline & R March & -0.15 & 0.88 & 16.7 & 2.5 & 16.1 & 2.7 & -0.55 \\
\hline \multirow{4}{*}{$\begin{array}{l}\text { IFFC-time } \\
\text { (ms) }\end{array}$} & L Walk & 2.756 & $0.010^{A D J}$ & 99.30 & 7.05 & 77.04 & 3.95 & 22.26 \\
\hline & R Walk & 3.809 & 0.001 & 92.34 & 3.60 & 72.88 & 3.62 & 19.46 \\
\hline & L March & 2.278 & 0.029 & 86.11 & 4.88 & 71.50 & 4.19 & 14.61 \\
\hline & R March & 2.755 & 0.009 & 81.31 & 3.63 & 66.79 & 3.80 & 14.51 \\
\hline \multirow{4}{*}{$\begin{array}{l}\text { HMHL- } \\
\text { IFC }\end{array}$} & L Walk & 1.133 & 0.265 & 0.56 & 0.01 & 0.54 & 0.01 & 0.01 \\
\hline & R Walk & 2.190 & 0.035 & 0.55 & 0.01 & 0.52 & 0.01 & 0.03 \\
\hline & L March & 0.100 & 0.921 & 0.55 & 0.01 & 0.55 & 0.01 & 0.00 \\
\hline & R March & -2.251 & 0.030 & 0.52 & 0.01 & 0.56 & 0.01 & -0.04 \\
\hline \multirow{4}{*}{ HMHL-5\% } & L Walk & 1.301 & 0.201 & 0.60 & 0.01 & 0.58 & 0.01 & 0.02 \\
\hline & R Walk & 0.479 & 0.635 & 0.59 & 0.01 & 0.58 & 0.01 & 0.01 \\
\hline & L March & 2.672 & 0.011 & 0.59 & 0.01 & 0.55 & 0.01 & 0.04 \\
\hline & R March & -2.444 & 0.019 & 0.55 & 0.01 & 0.58 & 0.01 & -0.03 \\
\hline \multirow{4}{*}{$\begin{array}{l}\text { HMHL- } \\
\text { IFFC }\end{array}$} & L Walk & 3.140 & 0.003 & 0.62 & 0.01 & 0.58 & 0.01 & 0.04 \\
\hline & R Walk & -1.840 & 0.074 & 0.58 & 0.01 & 0.61 & 0.01 & -0.03 \\
\hline & L March & 0.795 & 0.432 & 0.59 & 0.01 & 0.58 & 0.01 & 0.01 \\
\hline & R March & -2.336 & 0.025 & 0.57 & 0.01 & 0.60 & 0.01 & -0.03 \\
\hline
\end{tabular}


Table 3 - Optimal cut off points and their associated diagnostic indices for IFFCtime.

\begin{tabular}{|c|c|c|c|c|c|}
\hline Condition & $\begin{array}{c}\text { Optimal } \\
\text { cut-off } \\
\text { (ms) }\end{array}$ & $\begin{array}{c}\text { Sensitivity } \\
\text { (95\%Cl) }\end{array}$ & $\begin{array}{c}\text { Specificity } \\
\text { (95\%Cl) }\end{array}$ & $\begin{array}{c}\text { Positive } \\
\text { Likelihood } \\
\text { Ratio }(95 \% \mathrm{Cl})\end{array}$ & $\begin{array}{c}\text { Negative } \\
\text { Likelihood } \\
\text { Ratio }(95 \% \mathrm{Cl})\end{array}$ \\
\hline Walk & 76.6 & $82(60-93)$ & $63(41-80)$ & $2.2(1.2-4.0)$ & $0.29(0.11-0.79)$ \\
\hline March & 74.9 & $61(39-79)$ & $73(51-87)$ & $2.2(1.0-4.9)$ & $0.54(0.30-1.00)$ \\
\hline Walk+March & 76.3 & $70(50-84)$ & $71(51-85)$ & $2.4(1.2-4.8)$ & $0.42(0.22-0.82)$ \\
\hline
\end{tabular}


Figure 1 - Plantar pressure anatomical Zones defined by Footscan® software $(\mathrm{HM}$ : medial heel; HL: lateral heel; MF: midfoot; M1-5: metatarsals; T1: hallux; T2-5: toes)

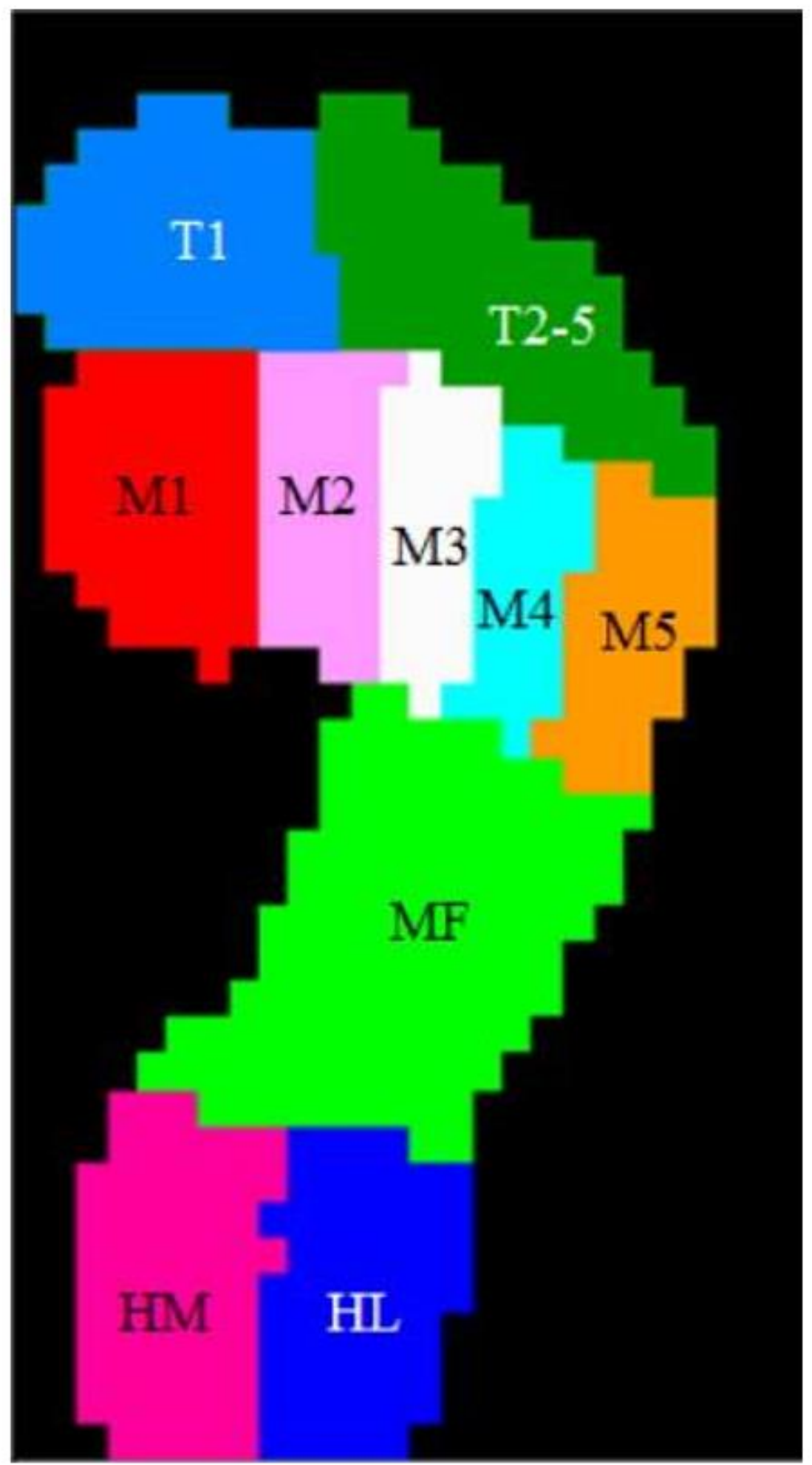


Figure 2 - Regression slopes for speed and FPA showing expected pattern of reducing Foot Progression Angle (FPA) with speed for CON (R2=0.105) $7,26,51,57,63$ but minimal effect of speed on FPA for PT group (R2=0.001).

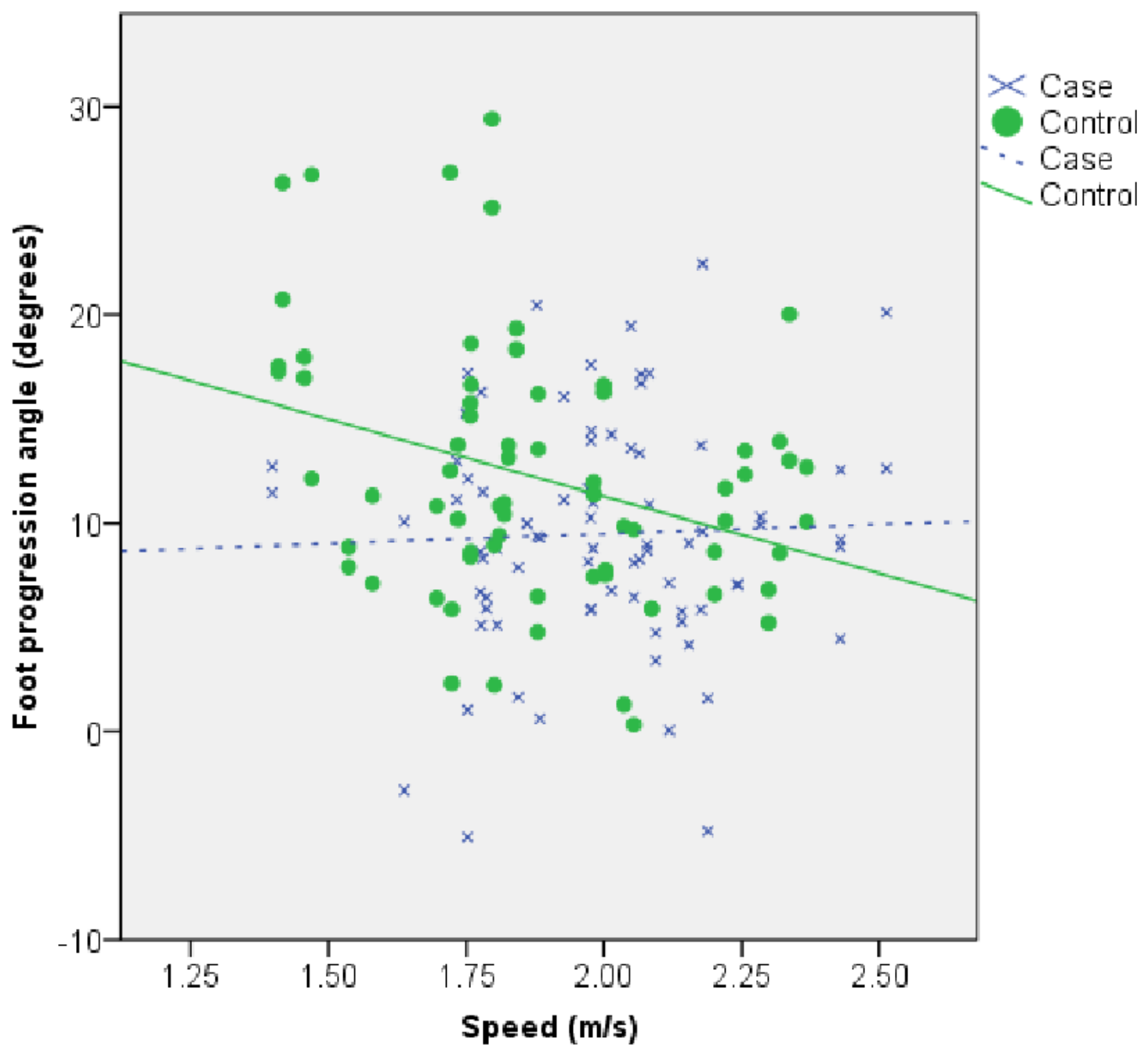


Figure 3 - IFFC-time ROC curve for combined data - all gait speeds

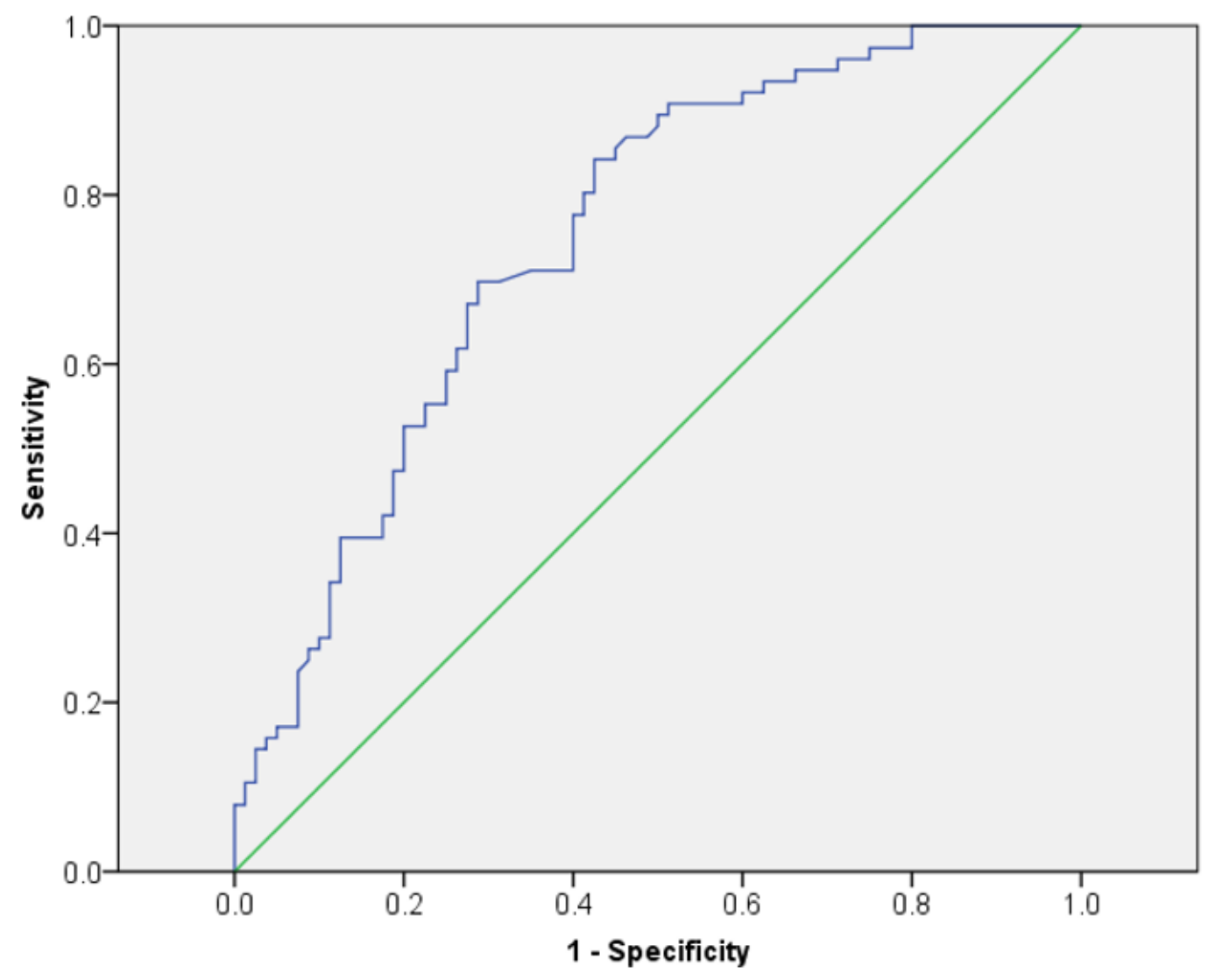




\section{Research Highlights}

1. Intramuscular Compartment Pressure (IMCP) is gold standard for diagnosis of CECS

2. Patients with CECS have increased rate of plantarflexion (IFFC) after heel strike

3. CECS cases appear less able to adapt foot progression angle to walking speed

4. Predictive value of plantarflexion rate similar to post-exercise IMCP

5. Further studies of IFFC in presence of CECS pain symptoms now indicated 